\title{
Current Situation on Flotation of Cu-Pb-Zn Sulfide Ore
}

\author{
Jian-Tao Lang ${ }^{1}$, Si-Qing Liü ${ }^{2, *}, \mathrm{Xu} \mathrm{Dong}^{3}$,Yi Pei ${ }^{4}$ \\ 1,2,3,4 Kunming University of Science and Technology, Kunming City, Yunnan Province, China \\ *1326847906@qq.com
}

\begin{abstract}
Keywords: Copper-lead-zinc sulfide ore, Flotation process, Separation of bulk concentrate, Flotation column

Abstract. In the flotation of copper - lead - zinc polymetallic sulfide ores, flotation separations of those valuable minerals have been a difficult problem due to their finely-associated intergrowth and similar flotability of these sulfide minerals. This paper summarizes the research status and progress of mineral processors both in China and abroad in recent years, mainly involving flotation process, separation of bulk concentrates and recent application of flotation column.
\end{abstract}

\section{Introduction}

Being important basic metal materials, copper, lead and zinc are widely used in various fields of the modern industry. These metals mainly exist in the forms of sulfides such as chalcopyrite, sphalerite, galena, etc. Moreover, the sulfide minerals are finely associated with each other in the forms of intergrowth and inlay. For instant, sphalerite usually contains droplet - like chalcopyrite formed by unmixing of solid solution ${ }^{[1]}$, and the dissemination grain of galena is relatively fine. All above mentioned factors lead a deficient liberation of minerals in grinding process, producing a low grade of concentrate with a mutual valuable minerals existing in concentrates in commercial operations of flotation. In order to solve this problem, relevant experimental works on the optimization of flotation separation process have been done, including the development of high efficiency flotation reagents and the application of flotation column.

\section{Floatation Process}

Preferential Flotation. When there are obvious differences in the flotability of minerals, the preferential flotation process is generally adopted. Various minerals are separated by flotation in the order of flotability from high to low. In a beneficiation tests of a $\mathrm{Cu}-\mathrm{Pb}-\mathrm{Zn}$ polymetallic sulfide ore, the sequential preferential flotation process by the order of copper- lead-zinc was adopted ${ }^{[2]}$, and the products, including copper concentrate assaying $19.84 \% \mathrm{Cu}$ at recovery of $60.25 \%$, lead concentrate assaying $72.34 \% \mathrm{~Pb}$ at recovery of $73.04 \%$, zinc concentrate assaying $50.55 \% \mathrm{Zn}$ at recovery of $88.46 \%$, were abtaned. However, some cases show that a preferential flotation to get copper and then a bulk flotation to get lead and zinc can also operate well. In more detail, the bulk flotation can be divided into two steps. First step is to float lead minerals preferentially and the second step is to float zinc minerals. The concentrate of them will be put together to produce a bulk product. In the separation test of a finely-disseminated polymetallic sulfide ore ${ }^{[3]}$, this flotation process was chosen and good performance was obtained, as the associated gold and silver were effectively recovered.

Partial Preferential Flotation. This process, often used in the flotation of complex polymetallic ores, is a priority flotation of the ores containing several sulfide minerals, where those minerals have similar flotability or close symbiotic relationship.

For a sulfide ore with high oxidation degree and fine particle disseminated, the partial preferential flotation process was adopted ${ }^{[4]}$. Namely, the copper and lead bulk concentrate was selected firstly and got separated. Then the zinc concentrate was obtained from the flotation tailings. Some better process indicators were acquired. On the basis of process mineralogy, according to the process "bulk flotation of copper and lead - separation of copper and lead - zinc flotation from tailings", a flotation test to a polymetallic ore was carrried out ${ }^{[5]}$. The final products with the recovery of $73.21 \% \mathrm{Cu}, 84.47 \% \mathrm{~Pb}$ and $80.80 \% \mathrm{Zn}$ were obtained, and the recovery of associated silver has been improved. 
Bulk Flotation. In the bulk flotation, all sulfide minerals are floated firstly, and then the separation of bulk concentrate will be carred out . The process is suitable to deal with the sulfide ore of low grade , in which many minerals are finely desseminated with each other in the forms of intergrowth and inlay. A sulfide ore of Tibet which is difficult to select was dealed with the process of bulk flotation ${ }^{[6]}$. Before the separation to get individual products, the bulk rough concentrate was transported to a mill due to the fine distribution of minerals. The copper concentrate assayed $14.48 \% \mathrm{Cu}$ at a recovery of $59.72 \%$; the grade of the lead and zinc concentrate were both more than $50 \%$ with the recovery of over $84 \%$. Besides the recovery of $\mathrm{Au}$ and $\mathrm{Ag}$ respectively reached $41.47 \%$ and $83.12 \%$, effective recovery of valuable precious metals was realized.

Combined Process with Gravity Concentration. In the study of mineral processing technology for a complex $\mathrm{Cu}-\mathrm{Pb}-\mathrm{Zn}$ sulfide ore in inner Mongolia, a complex symbiont was found among these minerals $^{[7]}$, so the conventional flotation flowsheet cannot be carried out. As the separation can not reached by the single flotation process, the combined technique of processing and gravity concentration has been raised to collect lead preferentially by the gravity difference. Then its tailings, which contained copper and zinc, has been treated by the pocess of bulk flotation. In the stage of gravity concentration, the grinding particle size was controled at $-0.15(\mathrm{~mm})$ as $95 \%$ to the shaking table. The experimental results showed that the separation effect was better than that of conventional process.

Metallurgical Process. As the polymetallic sulfide ore is getting more and more lean, miscellaneous and fine, sometimes a qualified concentrate and higher recovery can not be obtained by a single flotation process. Thus it is necessary to use the Combined technique of processing and metallurgy to treat the bulk concentrate by roasting-leaching or direct leaching (including microbiological leaching and chemical leaching) ${ }^{[8,9]}$. In this way, the grade and recovery of concentrate can be further improved. The grade of copper in the $\mathrm{Cu}-\mathrm{Pb}$ bulk concentrate is low, selected by the preferential flotation process in Xiacun Mine. The quality of product is not qualified, which also contains high grade of zinc and silver. In view of this problem, a test about the comprehensive recovery of $\mathrm{Cu}-\mathrm{Pb}$ bulk concentrate by oxygen pressure leaching was carried out ${ }^{[10]}$. In the first stage, the leaching rate of copper and zinc , under the optimal conditions, was as high as $98.89 \%$ and $94.92 \%$, respectively. And the lead and silver remained in a leaching residue. After the acid leaching in second stage, the leaching rate of lead and silver was reached $94 \%$ and $93 \%$, respectively.

Flotation Process by Slurry Potential Regulation. The flotation process by slurry potential regulation $^{[11]}$, according to the potential changes caused by the redox reaction ( electrochemical behavior ) inherent in the grinding and flotation process of sulphide ore, is a technique to adjust the flotation operation factors to achieve the potential regulation and improve the flotation process. Which has been adopted to treat an ore from Liaoning province. $\mathrm{CaO}$ was used as the adjusting agent of pulp potential. In the case of $-35(\mathrm{mV})$ and $\mathrm{pH} 9.1,-225.6(\mathrm{mV})$ and $\mathrm{pH} 11.4$, copper concentrate assaying $23.68 \% \mathrm{Cu}$ and lead concentrate assaying $51 \% \mathrm{~Pb}$ were obtained respectively. Zinc concentrate assaying $52 \% \mathrm{Zn}$ was obtained from the tailings activated by $\mathrm{CuSO}_{4}{ }^{[12]}$. A flotation test on a refractory lead-zinc ore was carried out ${ }^{[13]}$. It was found that the zinc sulfide and pyrite was effectively controlled without sodium cyanide by adjusting $\mathrm{pH}$ of the pulp with $\mathrm{CaO}$ when the $\mathrm{pH}$ value was 12 ( about -120 $\mathrm{mV})$. Under the condition of getting a similar concentrate grade, the $\mathrm{Pb}$ and $\mathrm{Zn}$ recovery was $9.08 \%$ and $6.66 \%$ higher than that of using cyanide, respectively.

\section{Separation of Bulk Concentrate}

The minerals in the bulk concentrate are often finely associated with each other, which is not conducive to the monomer dissociation. The activation of metal ion will appear in Grinding process and the pulp, leading a more similar floatability and increasing the difficulty to separate the bulk concentrate. In addition, there is always some residual agents from former flotation process in the bulk concentrate. The separation process will be interferenced with a bad decontamination. 
Reagent Removal from Bulk Concentrate. There are residual agents in bulk concentrate all the time, and the separation effect will be significantly improved with the removal of these agents. Several methods of decontamination commonly used in many concentrating plants are shown as follows ${ }^{[14]}$ :

a) After dehydrating the bulk concentrate to remove most of the agents, the product in the bottom will be treated with a flotation by adding water; b) To return the dehydrated products to a mill, the more fresh surfaces are exposed by scrubbing; c) Adding activated carbon to the pulp to adsorb the residual agents; d) Adding $\mathrm{Na}_{2} \mathrm{~S}$ to remove the collector-film on the surface of the mineral, and then dehydrating the concentrate.

Before the technical transformation, a bulk concentrate of $\mathrm{Cu}-\mathrm{Pb}$ from Inner Mongolia was treated to remove the residual agents by using activated carbon singly. The powdery activated carbon is easy to plug the control valve, which results fluctuations to the amount of activated carbon. As the dosage of activated carbon is excessive, a part of copper will float slowly and even flow into the lead concentrate. While the residual agents can't be completely removed with a less one, and the content of copper in the lead concentrate will rise. A technical optimization was implemented by the use of "concentrate dehydration+activated carbon" to decontaminate the residual agents, greatly improving the separation effect of $\mathrm{Cu}-\mathrm{Pb}$ bulk concentrate ${ }^{[15]}$.

Separation of Copper-Lead Bulk Concentrate. The main occurrence of copper and lead in the polymetallic sulfide is chalcopyrite and galena, respectively. In the actual production, the copper-lead bulk concentrate is generally enriched and then get separated because of the similar flotability. There are two methods of $\mathrm{Cu}-\mathrm{Pb}$ separation, restraining $\mathrm{Pb}$ to get $\mathrm{Cu}$ or in contrast. In the past, cyanide had been used as the depressant of copper, however with its toxicity and lack of alternative agents, the way restraining $\mathrm{Pb}$ to get $\mathrm{Cu}$ has been widely used.

The combined depressants of " $\mathrm{K}_{2} \mathrm{Cr}_{2} \mathrm{O}_{4}+\mathrm{CMC}+\mathrm{Z}-200$ " was used to treat a lead-zinc concentrate from Nanjing dy restraining lead to get copper ${ }^{[16]}$. As the bulk concentrate contained $50.8 \% \mathrm{~Pb}$ and $3.2 \% \mathrm{Cu}$, lead concentrate contained $6.58 \% \mathrm{Cu}$ and copper concentrate contained $0.59 \% \mathrm{~Pb}$ after getting separated. The good separation effect was obtained, while the amount of $\mathrm{K}_{2} \mathrm{Cr}_{2} \mathrm{O}_{4}$ was greatly reduced. In addition, with the development of new agents, the methods of suppressing copper to float lead has made some progress in the experiment and field in recent years.

Separation of Lead-Zinc Bulk Concentrate. The way of depressing zinc to collect lead is almost used to the separation of $\mathrm{Pb}-\mathrm{Zn}$, which mainly includes the use of $\mathrm{ZnSO}_{4}, \mathrm{H}_{2} \mathrm{SO}_{3}$ and cyanide. Due to the toxicity, cyanide has been gradually eliminated, and the former two agents are often used with sulfite and $\mathrm{Na}_{2} \mathrm{CO}_{3}$, because the effect is not good as used alone. A lead-zinc polymetallic raw ore of Myanmar contained 3.97\% $\mathrm{Pb}$ and $3.37 \% \mathrm{Zn}$, in which the content of lead oxide reached over 50\%. For the ore, a test was carried out to find the optimum agents and optimum dosage. Then the ethylthio thioate used as collector of lead sulfide and the combined depressants of " $\mathrm{ZnSO}_{4}+\mathrm{Na}_{2} \mathrm{SO}_{3}+\mathrm{Na}_{2} \mathrm{~S}$ " were determined $^{[17]}$. Finally, the products inclouding lead concentrate assaying $55.43 \% \mathrm{~Pb}$ at the recovery of $50.00 \%$ and zinc concentrate assaying $56.95 \% \mathrm{Zn}$ at the recovery of $83.20 \%$, were obtained.

The combination of GZT (the tannin-type organic compounds) and cyanide was used to the separation of lead-zinc, and a high-grade lead concentrate was obtained ${ }^{[18]}$. While reducing the amount of toxic agents, the recovery of lead was increased by $10.22 \%$ than that of the use of cyanide.

Separation of Copper-Zinc Bulk Concentrate. Sphalerite is the main occurrence of zinc minerals, always finely desseminated with copper sulfide in the polymetallic sulfide ore. It's difficult to separate copper and lead, because of the presence of harmful impurities(such as arsenopyrite, etc.) and the similar flotability with copper sulfide. Which is usually activited by free $\mathrm{Cu}^{2+}$ in the grinding and flotation process. An ore from Guangxi contained low copper and high zinc, in which the mineral partical size of copper was fine, mainly in the form of droplets included in the sphalerite. In addition, there were a lot of arsenopyrite in the ore. In the process of treated the ore, Z-200 was used to float the copper and the combined depressants of " $\mathrm{CaO}+\mathrm{ZnSO}_{4}+\mathrm{Na}_{2} \mathrm{SO}_{3}$ " was used to inhibit zinc and sulfur ${ }^{[19]}$. In addition, the combination of " $\mathrm{CaO}+\mathrm{y}-\mathrm{As}$ " was added to the tailings as the depressants of sulfur and arsenopyrite, with the butyl xanthate used as a collector of zinc. The final copper concentrate assayed 
$20.96 \% \mathrm{Cu}$ at the recovery of $75.20 \%$, and zinc concentrate assayed $48.36 \% \mathrm{Zn}$ at the recovery of $92.86 \%$. In both concentrate, the content of As was less than $0.45 \%$.

Separation of Zinc-Pyrite Bulk Concentrate. For the consideration of simple process and low cost of agents, $\mathrm{CaO}$ was usually used to adjust the $\mathrm{pH}$ of slurry, to depress pyite in the separation of zinc sulfide and pyrite. Some shortcomings were found in this method, for example, the equipments and pipes were easy to be scaled, and the pyrite concentrate is difficult to filter because of the large amounts of $\mathrm{CaO}$. In a small closed-circuit test and later industrial production test, a new depressant of sodium thioglycolate was added to effectively depress the pyrite ${ }^{[20]}$, while adjusting the high alkalinity pulp with lime, by which the grade and recovery of zinc concentrate got improved.

\section{Application of Flotation Column}

In the 1960s, flotation columns was used in Canadian ${ }^{[21]}$ to treat fine mineral particles for the first time, and since then which has been considered as one of the most important achievements in the field of mineral processing. As a new type of efficient flotation equipment, there is a obvious feature about flotation column ${ }^{[22]}$, which is the use of smooth countercurrent contact between mineral particles and fine bubbles, providing many opportunities to capture mineral particles. Compared with ordinary flotation cells, there are many advantages of flotation column, such as the simple structure, no mechanical moving parts, producing uniform fine bubbles, high enrichment ratio, high recovery and so on. Furthermore, it's beneficial for the recovery of fine mineral particles. Flotation column has been used in many processing plants. In the technical optimization of Xinjiang Ashele Processing Plant ${ }^{[23]}$, two CPT flotation column have been applied, and the products showed that the comprehensive recovery of copper was increased to $92.41 \%$, as the operating costs were greatly reduced.

\section{Conclusions and Outlook}

It has been a tough problem to get an effective flotation separation of the $\mathrm{Cu}-\mathrm{Pb}-\mathrm{Zn}$ polymetallic sulfide ores, due to their complex textures. According to the data of commercial operations and tests, it is an inevitable trend to develop new flotation agents with low cost and better effect. The flotation process should be adjusted timely according to similar flotation practices of the same kinds of ores. In recent decades, the flotation column has more advantages over the traditional flotation cells, especially for the recovery of finely-disseminated mineral particles, which is more adaptable to the current changes in processing of the refractory mineral resources. There is a bright future for the application of flotation column.

\section{References}

[1] Jiang C.L., Qu S.S., Wang L.Z. Study on the Occurrence of Cu-Pb-Zn-Ag in a Polymetallic Ore in Inner Mongolia and the Mineralogical Factors Affecting Mineral Processing[J]. Metallurgical Engineering, 2015, (z1): 41-44

[2] Wang X.L. Study on Beneficiation Process and Mechanism of a Cu-Pb- $\mathrm{Zn}$ Polymetallic Sulfide Ore in Qibaoshan[D]. Jiangxi University of Science and Technology, 2012.

[3] Ai G.H., Zhou Y. Experimental Study on Flotation Process of a Finely Disseminated Cu-Pb-Zn Polymetallic Ore[J]. Metal Mine, 2004, (10): 36-38.

[4] Hu X.L., Zheng W.M. Study on the Beneficiation of a Refractory Copper-Lead-Zinc Ore[J]. Gold, 2015, (12): 57-62.

[5] Ai G.H., Wu H., Yan H.S., Liu, Y.F. Flotation Process on a Copper-Lead-Zinc Polymetallic Ore in Sichuan[J]. Nonferrous Metals Engineering, 2015, (6): 45-50.

[6] Zhao Q., Ding S.R., Zhou N., et al. Experimental Study on Beneficiation of a Copper-Rich Lead-Zinc Sulfide Ore in Tibet[J]. Mineral Resources Protection and Utilization, 2017, (2): 39-46. 
[7] Li W.J., Song Y.S., Liu S., et al. Study on Mineral Processing Technology of a Complex Copper-Lead-Zinc Sulfide Ore in Inner Mongolia[J]. Metal Mine, 2012, (6): 79-84.

[8] Rehman M, Anwar M A, Iqbal M, et al. Bioleaching of High Grade Pb-Zn Ore by Mesophilic and Moderately Thermophilic Iron and Sulphur Oxidizers[J]. Hydrometallurgy,2009,97:1-7.

[9] Zhou J., Liao Y.L., Li B.J., Huang F.R. Research Status and Progress in Separation of Valuable Metals in Polymetallic Complex Sulphide[J]. Progress in Chemistry, 2015, (1): 252-257.

[10] Yang J.K., Xu B., Yang D.J., et al. A Comprehensive Recovery Process for Oxygen Pressure Leaching of Complex Copper-Lead Concentrates[J]. Kunming University of Science and Technology, 2011,36 (2) 15.

[11] Gu G.H., Wang D.Z., Liu R.Y., et al. Potential Regulation of Flotation and Primary Potential Flotation Technology[J]. Nonferrous Metals, 2000,52 (2): 18-21.

[12] Liu B., Hao L.Y., et al. Potential Regulation of Preferential Flotation on a Copper-Lead-Zinc Sulfide Ore in Liaoning[J]. Metal Mine, 2016, (3): 82-85.

[13] Gan Y.G. Primary potential regulation of Flotation on a Refractory Lead-Zinc Ore[J]. Chinese Mine Engineering, 2015,44 (1): 1-6.

[14] Hu Y.H., Feng Q.M. Mineral Resources Processing Technology and Equipment[M]. Beijing: Science Press, 2014: 251-252.

[15] Zhou T., Shi W.H., Yu J.H., et al . Optimization of Beneficiation Technology of a Refractory Copper-Lead-Zinc Polymetallic Ore in Inner Mongolia[J]. Metal Mine, 2013, (5): 82-87,91.

[16] Zhang J.C. Study on Copper-Lead Separation of Lead-Zinc-Silver Mine in Nanjing and Application[D]. Jiangxi University of Science and Technology, 2012.

[17] Yang J.L., Liu Q.Y., et al . Flotation Experiment of a Complex Pb-Zn Polymetallic Ore in Myanmar[J]. Non-Ferrous Metals (Mineral Processing Section), 2012, (2): 39-43.

[18] Zhou D.Y. Study on the Separation of a Lead-Zinc Sulfide Ore in Changpo Plant[J]. Public Science and Technology, 2012, (1): 111-113.

[19] Liu Z.S. Flotation Process on a Refractory Copper-Zinc Sulfide Ore with Low Copper and Arsenic[D]. Jiangxi University of Science and Technology, 2013.

[20] Lin H.H., Wu H.Y., et al. Application of Sodium Thioglycollate in Separation of Zinc and Sulfur[J]. China Tungsten Industry, 2014, (4): 32-34.

[21] Hulya Kursun, Ugur Ulusoy. Zinc Recovery From Lead-Zinc-Copper Complex Ores by Using Column Flotation[J]. Mineral Processing and Extractive Metallurgy Review, 2012.

[22] Guo H.B. Application of Large Flotation Column in Roughing Operation of Molybdenum Ore [J]. New Technology and New Products, 2013, (6): 180.

[23] Lin S.R. Application of CPT Flotation Column in Xinjiang Ashele Processing Plant[J]. Xinjiang Nonferrous Metals, 2016,39 (2): 77-79,82. 